\title{
Effects of Kwashiorkor on Cortical and Trabecular Bone
}

\author{
PETER ADAMS and F. R. BERRIDGE \\ From the Infant Nutrition Research Division, Dunn Nutritional Laboratory, \\ University of Cambridge and Medical Research Council; and Addenbrooke's Hospital, Cambridge
}

During the normal growth and development of man and animals the bones grow in length and width and undergo progressive changes in their architecture, a process known as maturation. These normal processes are governed by numerous and complex forces but one of them, the plane of nutrition during the growing period, is of major importance. Undernourished children are small in stature and have bones which are at an earlier stage of development than normal (Berridge and Prior, 1954; Jones and Dean, 1956). These disturbances of skeletal growth and maturation are found in children deprived of calories (marasmus) and protein (kwashiorkor); experimental studies have confirmed these clinical observations. When animals are subjected to severe and prolonged undernutrition from early in their development, growth is retarded and the bones are abnormal in structure and composition; this happens with experimentally-induced deficiencies of calories (Dickerson and McCance, 1961; and of protein (Platt and Stewart, 1962; El-Maraghi, Platt, and Stewart, 1965), though the changes produced are not identical in the 2 conditions (Adams, 1969).

Children with kwashiorkor have small bones which are less mature than normal (Jones and Dean, 1956) and which commonly show transverse lines of arrested growth visible at $x$-ray (Jones and Dean, 1956; Platt, Stewart, and Platt, 1963); a deficiency of cortical bone has also been found (Garn et al., 1964). Wayburne (1968) has reported a loss of trabecular bone in South African children with kwashiorkor; but many of them have rickets, and this complicates the precise interpretation of bony changes and of the role of protein deficiency in their production. In contrast to other findings, Reichman and Stein (1968) reported few abnormalities in the bones of Bantu children with protein deficiency.

Received March 26, 1969.
Kwashiorkor is a clinical syndrome in which prominent features are growth failure, generalized oedema, hypoproteinaemia, and changes in the skin and dermal appendages. The condition is recognized in many countries, though regional differences exist with regard to the age of the affected children and the presence of other symptoms and signs. In Uganda, kwashiorkor is found in children aged 6 to 48 months who have been reared since weaning on 'Matooke', a cooking banana which provides a very small amount of protein in relation to the caloric value of the diet. The banana diet is not only deficient in protein but also in calcium and phosphorus. The estimated daily dietary intake of calcium of the children who develop kwashiorkor is $100 \mathrm{mg}$. or less (I.H.E. Rutishauser; 1967, personal communication). In Uganda kwashiorkor is entirely the result of protein deficiency and rickets is not a feature of the disease.

We have examined the hand $x$-rays of Ugandan children with kwashiorkor, some of whom had been studied previously by Jones and Dean (1956); and report here the effects of this disorder on cortical and trabecular bone.

\section{Material and Methods}

There were 19 children with kwashiorkor and these were compared with 17 healthy children matched for age and sex.

The children with kwashiorkor comprised 8 females and 11 males aged 6 to 37 months; they were all of the Baganda tribe. The diagnosis of kwashiorkor was made according to the clinical features of the disease as seen in Kampala (Trowell, Davies, and Dean, 1954); and the presence of certain biochemical abnormalities which are typical of the disorder (Dean and Schwartz, 1953).

The healthy children comprised 7 females and 10 males aged 7 to 36 months. These well-nourished children were of the Baganda tribe and their growth patterns were normal according to local standards (Rutishauser, 1965).

Posterior-anterior $x$-rays of the hands of the sick 
TABLE I

Body Weight and Height in Normal Children and Children with Kwashiorkor (mean $\pm S E$ )

\begin{tabular}{|c|c|c|c|}
\hline & Age (mth.) & Weight (kg.) & Length (cm.) \\
\hline $\begin{array}{l}\text { Kwashiorkor } \\
\begin{array}{l}\text { (19) } \\
\text { Normal (17) }\end{array} \\
\text { Probability . }\end{array}$ & $\begin{array}{c}20 \cdot 61 \pm 2 \cdot 0 \\
19 \cdot 76 \pm 1 \cdot 6 \\
>0 \cdot 7\end{array}$ & $\begin{array}{c}7.7 \pm 0.56 \\
10.32 \pm 0.6 \\
<0.001\end{array}$ & $\begin{array}{c}73 \cdot 18 \pm 1 \cdot 95 \\
79 \cdot 37 \pm 1 \cdot 13 \\
<0.02\end{array}$ \\
\hline
\end{tabular}

Figures in parentheses are numbers in each group.

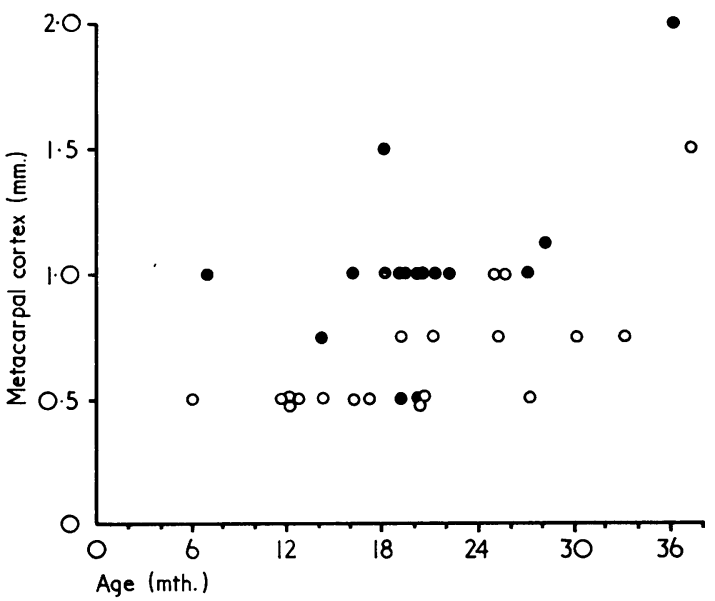

Fig. 1.-Thickness of the metacarpal cortex in normal children (closed circles), and in children with kwashiorkor (open circles).

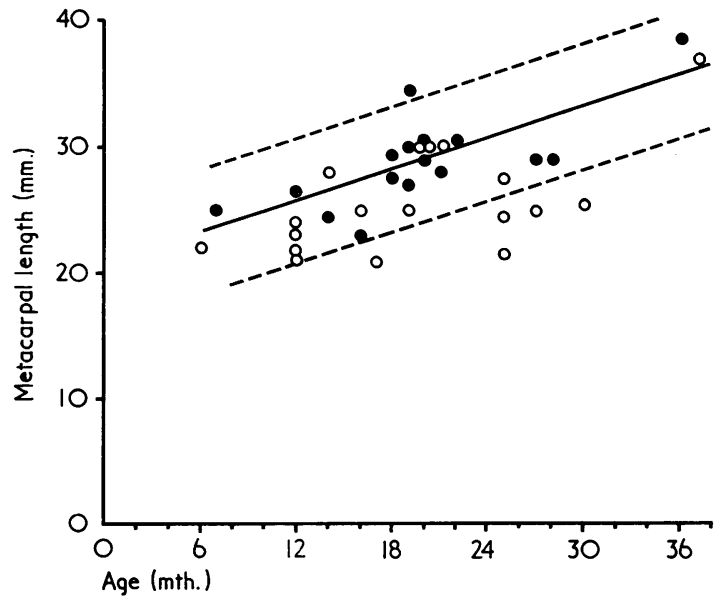

FIG. 2.-Relation between metacarpal length and chronological age showing regression line for normal children (closed circles) and 95\% confidence limits (----). Open circles represent children with kwashiorkor. children were made as part of the routine investigation of all children admitted to the MRC unit, Kampala, and were made on the day of or the day after admission. The $x$-rays were examined by two observers; one made measurements of the second metacarpal and the other made observations of the appearance of the bones and an assessment of bone age.

Measurements of the second metacarpal were made directly from the $x$-rays with callipers and ruler. The width of the metacarpal and the thickness of the cortex were measured at the mid-shaft; the mid-point of the shaft of the metacarpal was found with a protractor. The length of the metacarpal was also measured. The amount of trabecular bone in the tubular bones of the hand was judged subjectively and graded into 3 categories; a good and a poor group indicating normal and definitely subnormal amounts of trabecular bone respectively, and an intermediate group which we called 'fair' in which the amount of trabecular bone lay between the 2 extremes. The presence or absence of transverse lines at the distal ends of the radius and ulna was also noted. Bone age was assessed from the radiographic atlas of Greulich and Pyle (1950).

The $x$-rays were examined separately by the 2 observers and were allocated to them in random order. After the observations and measurements had been made the $x$-rays were allocated into a different random order and were examined again.

\section{Results}

Table I shows that on average the children with kwashiorkor weighed significantly less $(p<0.001)$ and were significantly shorter $(p<0.02)$ than the normal children matched for age and sex.

The amount of cortical bone in the metacarpal was small in all the children, but it was consistently and significantly less $(p<0.005)$ in those with kwashiorkor (Fig. 1). The length of the metacarpal tended to be smaller than normal in the children with kwashiorkor (Fig. 2). Metacarpal length and chronological age were significantly related in the normal children $(r=0.73 ; p<0.001)$; the regression line and $95 \%$ confidence limits of this relation are shown in Fig. 2. In 5 children with kwashiorkor the length of the metacarpal was significantly smaller than normal (Fig. 2). The mean width of the metacarpal did not differ significantly between the two groups. Thus, the metacarpals of the children with kwashiorkor were wider for their length than normal. There was a highly significant correlation $(r=0.96$; $\mathrm{p}<0.001$ ) between the length of the second metacarpal and the total length of the body in the normal children; Fig. 3 shows the regression line and $95 \%$ confidence limits of this relation. All the children with kwashiorkor conform to this relation (Fig. 3). 
TABLE II

Assessments of Trabecular Bone Mass in Metacarpals of Normal Children and Children with Kwashiorkor

\begin{tabular}{|c|c|c|c|c|}
\hline & \multicolumn{3}{|c|}{ Trabecular Pattern } & \multirow{2}{*}{ Total } \\
\hline & Good & Fair & Poor & \\
\hline $\begin{array}{l}\text { Kwashiorker } \\
\text { Normal }\end{array}$ & $\begin{array}{r}3 \\
11\end{array}$ & $\begin{array}{l}2 \\
4\end{array}$ & $\begin{array}{r}14 \\
2\end{array}$ & $\begin{array}{l}19 \\
17\end{array}$ \\
\hline Total .. & 14 & 6 & 16 & 36 \\
\hline
\end{tabular}

No individual differences in the subjective assessments of trabecular bone mass were found between the two examinations of the $x$-rays. The assessments of trabecular bone mass in the normal children and in the children with kwashiorkor are shown in Table II. There was significantly less trabecular bone in the children with kwashiorkor; this is true whether the intermediate (fair) group is included with the poor group $\left(\chi^{2}=\right.$ 7.09 d.f. $=1, p<0.01$ ) or with the good group $\left(\chi^{2}=11.54\right.$ d.f. $\left.=1, \mathrm{p}<0.001\right)$. The children with definitely subnormal amounts of trabecular bone were in general those with the least amount of cortical bone. Horizontal lines of increased calcification were seen at the distal ends of the radius and ulna in 6 normal children and in 12 with kwashiorkor; the incidence of these lines in the 2 groups did not differ significantly $\left(\chi^{2}=1 \cdot 783\right.$; d.f. $=1 ; 0.2>p>0.1)$. The presence of horizontal lines was not related to the amount of trabecular bone in the hand bones $\left(x^{2}=2.922\right.$ d.f. $=1,0 \cdot 1>\mathrm{p}>0.05$ ).

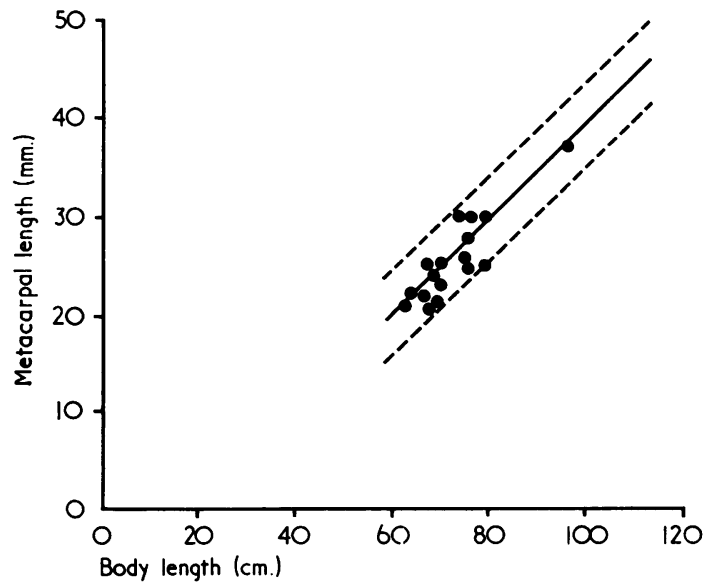

FIG. 3.-Relation between metacarpal length and body length showing regression line for normal children and $95 \%$ confidence limits (- - - ). Closed circles represent children with kwashiorkor.

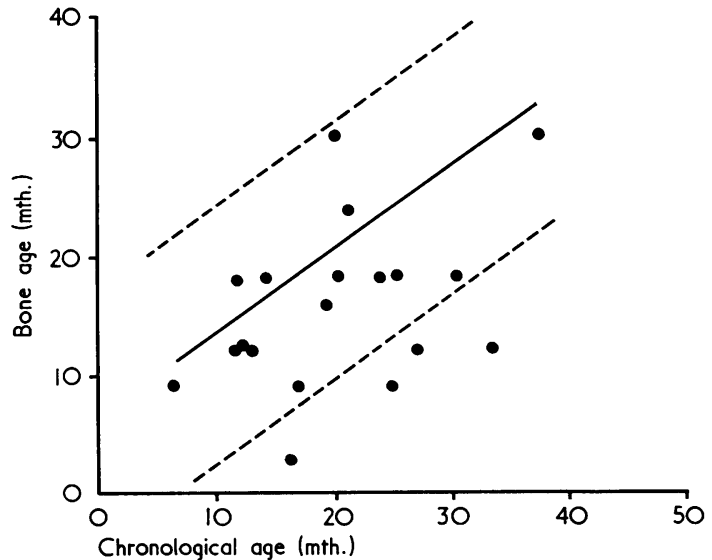

FIG. 4.-Relation between bone age and chronological age showing regression line for normal children and $95 \%$ confidence limits (--- ). Closed circles represent children with kwashiorkor.

Bone age and chronological age were significantly related in the normal children $(r=0.65, p<0.01)$; the regression line and $95 \%$ confidence limits of this relation are shown in Fig. 4. Four children with kwashiorkor had a significantly retarded bone age (Fig. 4). The mean difference between bone age and chronological age of the normal children $(0.44$ months) was significantly greater $(p<0.05)$ than that of the children with kwashiorkor ( -4.47 months). The length of the second metacarpal was significantly related to bone age $(r=0.84, p<0.001)$ in the normal children; Fig. 5 shows the regression line and 95\% confidence limits of this relation. For most

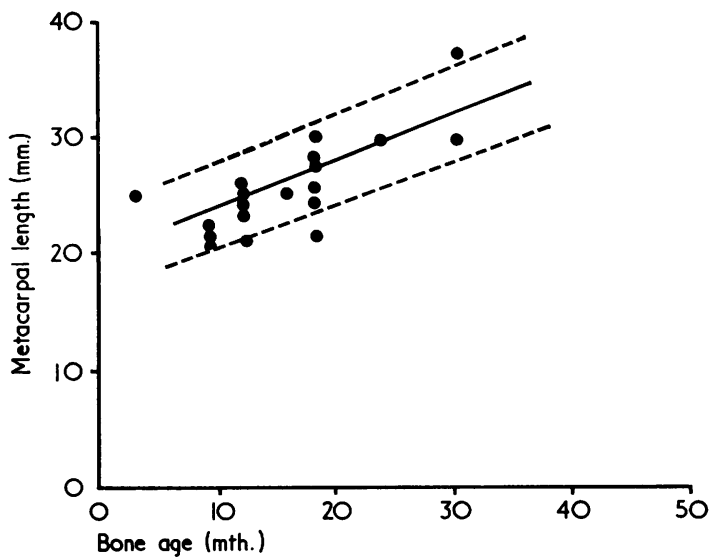

FIG. 5.-Relation between metacarpal length and bone age showing regression line for normal children and $95 \%$ confidence limits (--- ). Closed circles represent children with kwashiorkor. 
children with kwashiorkor the length of the metacarpal was appropriate for the degree of skeletal maturation (Fig. 5).

There were no radiological or other features of rickets in the children with kwashiorkor.

\section{Discussion}

We have found 2 abnormalities in the hand bones of children with kwashiorkor in addition to those reported by Jones and Dean (1956); these are a paucity of cortical and of trabecular bone.

The measurement of the thickness of the metacarpal cortex at the mid-shaft provides a good estimate of cortical bone mass (Morgan et al., 1967). In the children with kwashiorkor there was significantly less cortical bone in this metacarpal than normal. Though the amount of trabecular bone was judged subjectively from the $x$-ray appearances of the bones, we have no doubt that there was less trabecular bone in the metacarpals of children with kwashiorkor than normal. These changes in the amounts of cortical and trabecular bone resemble those found in the long bones of animals with experimentally-induced protein deficiency (Adams, 1969). The length of the metacarpal and the total body length of the children with kwashiorkor were on average smaller than normal; but the normal relation between metacarpal and body length was not disturbed. This suggests that the retarded growth of the metacarpal in kwashiorkor is a direct reflection of the general retardation of skeletal growth which is characteristic of the disorder.

Lines of arrested growth were seen at the distal ends of the radius and ulna in both the normal and abnormal children. The incidence of these lines was not related to the presence of kwashiorkor or to the amount of trabecular bone in the metacarpal. These findings are not surprising, since transverse lines visible at the ends of the long bones are seen commonly in apparently healthy children; and they appear even after minor illnesses in childhood.

We have confirmed the observation of Jones and Dean (1956) who found that children with kwashiorkor had delayed skeletal maturation. We found that bone age was related to metacarpal length in the normal children; and that in general metacarpal length was appropriate for the degree of skeletal maturation in the children with kwashiorkor. This does not seem to be true of experimentally-induced protein deficiency where bone growth appears to be retarded to a greater extent than skeletal maturation (Adams, 1969).

The precise mechanisms responsible for the retarded bone growth, delayed maturation, and the loss of trabecular and cortical bone in children with kwashiorkor are not clearly defined. The children studied here have been reared since weaning on a diet poor in protein, calcium, and phosphorus. Lack of protein must be the major factor in the disturbance of growth because protein is an essential requirement for the normal growth of all bodily tissues; and growth is reduced when there is an inadequate amount of protein in the diet. A major feature of experimentally-induced protein deficiency is retarded growth, though, as with children with kwashiorkor, the bodily growth of experimental animals does not cease. A disturbance of skeletal maturation is common to marasmus and kwashiorkor and has been produced experimentally; the mechanisms responsible remain to be identified.

Detailed studies of calcium metabolism have not been made in children with kwashiorkor; but we do know that the dietary calcium is minimal and that there are negligible amounts of calcium in the urine (Widdowson, 1969). The small amount of protein in the diet may adversely influence calcium absorption from the gut (McCance, Widdowson, and Lehmann, 1942); yet despite this the bones do grow in length, albeit slowly. There was no evidence of rickets in the children with kwashiorkor, which indicates that the bone formed during the period of protein deprivation is mineralized normally. Dickerson and John (1969) found in children with kwashiorkor that there was less bone tissue than normal but that the chemical composition of the non-epiphysial parts of the femur was normal. That the bones continue to grow suggests that the children are not in negative external mineral balance. The paucity of calcium in the diet suggests that growth in length of the bones is achieved partly through the internal recycling and deposition of bone mineral already present in the skeleton. Such an internal redistribution of bone mineral would explain the paucity of cortical and trabecular bone found in the shafts of bones of children with kwashiorkor. Measurements of bone turnover have not been made in children with kwashiorkor, but the loss of cortical and trabecular bone from the shafts of the bones suggests that bone resorption exceeds bone formation at these sites. Experimental studies tend to support this suggestion; in experimentally-induced protein deficiency bone resorption exceeds bone formation when measured at the mid-shaft of long bones ( $P$. Adams and J. Jowsey, 1968, unpublished observations).

\section{Summary}

The $x$-ray appearances of the hand bones of 
Ugandan children with kwashiorkor were compared with those of a group of normal children matched for age and sex. The children with kwashiorkor were found to have less cortical and trabecular bone than normal. The previously noted observation that skeletal maturation is sometimes delayed in kwashiorkor was confirmed.

We wish to thank Professor R. A. McCance and Dr. E. M. Widdowson for their encouragement and for much helpful advice and criticism. We are particularly indebted to Miss I. H. E. Rutishauser of the M.R.C. Child Nutrition Research Unit, Kampala, for providing us with the $x$-rays and clinical details of the cases.

\section{REFERENCES}

Adams P. (1969). The effects of experimental protein deficiency on the growth and development of long bones. In Symposium Ossium. Ed. by A. M. Jelliffe. Livingstone, Edinburgh.

Berridge, F. R., and Prior, K. M. (1954). The skeletal development of the children at the beginning and end of the period of experimental feeding. Spec. Rep. Ser. med. Res. Coun. (Lond.) No. 287, 119.

Dean, R. F. A., and Schwartz, R. (1953). The serum chemistry in uncomplicated kwashiorkor. Brit. F. Nutr., 7, 131

Dickerson, J. W. T., and John, P. M. V. (1969). The effect of protein-calorie malnutrition on the composition of the human femur. ibid., 23, 917.

$\longrightarrow$, and McCance, R. A. (1961). Severe undernutrition in growing and adult animals. 8. The dimensions and chemistry of the long bones. ibid., 15, 567.

El-Maraghi, N. R. H., Platt, B. S., and Stewart, R. J. C. (1965) The effect of the interaction of dietary protein and calcium on the growth and maintenance of the bones of young, adult and aged rats. ibid., 19, 491.

Garn, S. M., Rohmann, C. G., Behár, M., Viteri, F., and Guzmán, M. A. (1964). Compact bone deficiency in protein-calorie malnutrition. Science, 145, 1444.

Greulich, W. W., and Pyle, S. I. (1950). Radiographic Atlas of Skeletal Development of the Hand and Wrist. Stanford University Press, Stanford.

Jones, P. R. M., and Dean, R. F. A. (1956). The effects of kwashiorkor on the development of the bones of the hand. $\mathcal{F}$. trop. Pediat., 2, 51.

McCance, R. A., Widdowson, E. M., and Lehmann, H. (1942). The effect of protein intake on the absorption of calcium and magnesium. Biochem. $\mathcal{F}$., 36, 686.

Morgan, D. B., Spiers, F. R., Pulvertaft, C. N., and Fourman, P. (1967). The amount of bone in the metacarpal and the phalanx according to age and sex. Clin. Radiol., 18, 101.

Platt, B. S., and Stewart, R. J. C. (1962). Transverse trabeculae and osteoporosis in bones in experimental protein-calorie deficiency. Brit. F. Nutr., 16, 483.

Platt, H. S., Stewart, R. J. C., and Platt, B. S. (1963). Transverse trabeculae in the bones of malnourished children. Proc. Nutr. Soc., 22, xxix.

Reichman, P., and Stein, H. (1968). Radiological features noted on plain radiographs in malnutrition in African children. Brit. F. Radiol., 41, 296.

Rutishauser, I. H. E. (1965). Heights and weights of middle class Baganda children. Lancet, 2, 565.

Trowell, H. C., Davies, J. N. P., and Dean, R. F. A. (1954). Kwashiorkor. E. Arnold, London.

Wayburne, S. (1968). Malnutrition in Johannesburg. In Calorie Deficiencies and Protein Deficiencies, p. 7. Ed.by R. A. McCance and E. M. Widdowson. Churchill, London.

Widdowson, E. M. (1969). In preparation.

Correspondence to Dr. Peter Adams, Dunn Nutritional Laboratory, Milton Road, Cambridge. 